\title{
Chapter 4 \\ Rethinking Adoption and Diffusion as a Collective Social Process: Towards an Interactional Perspective
}

\author{
Cees Leeuwis and Noelle Aarts
}

\subsection{Introduction}

While many scholars and practitioners use the term 'agricultural development', the meaning of the concept is ambiguous, as there exist different views on the desired model of agriculture. For example, some associate 'agricultural development' with an 'agro-ecological' future, while others make a plea for 'sustainable intensification'. Regardless of such view, agricultural development is somehow associated with changes in agricultural practices, including the so-called adoption of technological and other types of innovation that are congruent with a proposed agricultural development trajectory. The term adoption has a long tradition and has been used in many studies (Rogers 1962; Loevinsohn et al. 2012, 2013). Frequently, such studies assess the adoption of new practices and technologies as part of an effort to determine the success or failure of development interventions. At the same time, several scholars have pointed to difficulties with regard to such a use of the term 'adoption' in research and development practice (Loevinsohn et al. 2012, 2013; Glover et al. 2016). It is argued that it is far from clear when someone can be regarded as having actually 'adopted' a practice or technology; should we speak of adoption when someone uses a new practice on a small portion of a farm, for a short period of time, or for merely opportunistic reasons (e.g. to get access to a service or network)? Another critique is that the term obscures the socio-technical character of change, as well as emergent forms of creolisation, making and redesign that frequently

\footnotetext{
C. Leeuwis $(\bowtie)$

Knowledge, Technology and Innovation group at the Section Communication, Philosophy and Technology, Wageningen University, Wageningen, The Netherlands

e-mail: cees.leeuwis@wur.nl
}

N. Aarts

Socio-Ecological Interactions group at the Institute for Science in Society, Radboud University, Nijmegen, The Netherlands

e-mail: noelle.aarts@ru.nl 
occur when farmers engage with new technologies (Glover et al. 2016). In other words, that what is supposedly adopted may actually have changed and become contextually adapted. Such critiques are valid and indeed render the concept of 'adoption' to be rather ambiguous.

In this chapter, we do not focus on the issue of how to precisely define or measure adoption, nor on the processes of adaptation that are likely to be involved. Instead, we focus on theories and modes of thinking that have been used to explain and understand why people do or do not 'adopt' a novel practice. This regardless of how sizable, durable or adaptive such changes may be. Such theoretical explanations include two interrelated dimensions: (a) factors or variables that are seen to influence whether people adopt or not and (b) the kinds of dynamic processes that are seen to be at work in shaping such factors. In relation to these, we will argue that adoption theories and technology uptake models have tended to regard adoption as a largely individual process and that they have thereby overlooked critically important interdependencies in the process of adoption. Subsequently, we complement individualist models for explaining adoption with sociological variables and then work towards an interactional perspective on the adoption process. Eventually, we will briefly highlight relevant conceptual and practical implications of our perspective with regard to some topical issues in development intervention, notably the idea of 'scaling' and the wish to support adoption and scaling with the help of information and communication technology for agriculture (ICT4Ag).

\subsection{Adoption Seen as an Individual Argumentative Process}

\subsubsection{Everett Rogers' Seminal Work}

In 1962, Everett Rogers made a synthesis of more than 500 studies in his famous book 'diffusion of innovations' in which adoption is a central theme. At this point in time, adoption is regarded as a process of individual decision-making, even though it is recognised that individuals are part of a broader system (Rogers 1962). Rogers argues that adoption (or rejection) of an innovation arises from a process in which individuals go through several stages (see Table 4.1). The process is essentially seen as a cognitive process in which various sources of information may play an important role. In line with this, provision of particular information was seen as a key activity in supporting individuals in the process of arriving at an adoption or rejection decision (Van den Ban 1963; Van den Ban and Hawkins 1996).

According to Rogers, the way an adoption process evolves is further shaped by the antecedents of the individual involved (his or her values, status, cosmopoliteness, etc.), his or her perception of the situation and the perceived characteristics of the innovation. This includes how individuals view the relative advantage of the innovation, the extent to which the innovation is regarded as compatible with existing practices and the perceived complexity of using the innovation in the context at 
Table 4.1 The adoption process according to Rogers 1962 (and 1995) linked to information that is relevant per stage (Van den Ban 1963; Van den Ban and Hawkins 1996; Leeuwis 2004)

\begin{tabular}{l|l}
\hline $\begin{array}{l}\text { Stages in the adoption process } \\
\text { (below in brackets: renaming of } \\
\text { stage in Rogers 1995) }\end{array}$ & $\begin{array}{l}\text { Nature of knowledge and information required and/or } \\
\text { searched for }\end{array}$ \\
\hline $\begin{array}{l}\text { Stage 1: Awareness } \\
\text { of the existence of a new } \\
\text { innovation or policy measure } \\
\text { (Knowledge) }\end{array}$ & $\begin{array}{l}\text { Information clarifying the existence of tensions and } \\
\text { problems addressed by the innovation or policy measure }\end{array}$ \\
\hline $\begin{array}{l}\text { Stage 2: Interest } \\
\text { collecting further information } \\
\text { about it } \\
\text { (Persuasion) }\end{array}$ & $\begin{array}{l}\text { Information about the availability of promising solutions } \\
\text { that may be relevant in the prospective user context }\end{array}$ \\
\hline $\begin{array}{l}\text { Stage 3: Evaluation } \\
\text { reflection on its advantages and } \\
\text { disadvantages } \\
\text { (Decision) }\end{array}$ & $\begin{array}{l}\text { Information about relative advantages and disadvantages of } \\
\text { alternative solutions }\end{array}$ \\
\hline $\begin{array}{l}\text { Stage 4: Trial } \\
\text { testing innovations/behaviour } \\
\text { changes on a small scale } \\
\text { (Implementation) }\end{array}$ & $\begin{array}{l}\text { Feedback information from one's own or other people's } \\
\text { practical experiences }\end{array}$ \\
\hline $\begin{array}{l}\text { Stage 5: Adoption (or Rejection) } \\
\text { applying innovations/behaviour } \\
\text { changes } \\
\text { (Confirmation) }\end{array}$ & Information reinforcing the adoption decision made \\
\hline
\end{tabular}

hand. Some of these perceptions are in fact reconfigured during the adoption process; based on information acquired, a person's perception of the situation and/or the perception of the relative advantages of the innovation may change.

Rogers seminal synthesis has been amended and developed further since its appearance in 1962 (see Rogers 1995). Moreover, the overall perspective and largely linear paradigm that it reflects have been criticised sharply (see, e.g. Leeuwis 2004).

\subsubsection{Social-Psychological Follow-Up}

Rogers' focus on individual decision-making has inspired many scholars to apply social-psychological theories and models to the issue of adoption (Taherdoost 2018). Such models include the theory of reasoned action (TRA, Fishbein and Ajzen 1975), the theory of planned behaviour (TPB, Ajzen 1985, 1991), different versions of the technology acceptance model (Davis et al. 1989; Venkatesh and Davis 2000), social cognitive theory (SCT, Rana and Dwivedi 2015) and uses and gratification theory (U\&G, West and Turner 2010). Several such models were integrated in the unified theory of acceptance and use of technology (UTAUT) by Venkatesh et al. (2003). 
While these models differ from each other in several respects, they tend to include a number of perceptual, cognitive and/or mental variables, often labelled as 'determinants' of adoption behaviour. Some key categories of determinants are listed below (see Table 4.2). As shown in Fig. 4.1, such determinants are often regarded as being influenced by personality traits and demographic variables.

\subsection{Considerations Related to Interdependence: Towards an Interactional View on Reasons for (Non)adoption}

The individualist perspective on adoption has been criticised for its simplistic notion of adoption (see the introduction), its pro-innovation bias, its linear connotations and its lack of attention for social and institutional dimensions of innovation (see Leeuwis 2004). Similarly, it has been argued that the kind of social-psychological theories referred to above overemphasise cognitive and rational processes and do not sufficiently acknowledge limitations in our cognitive capacities (Kahneman 2011) and the importance of heuristics, routine and/or impulsive triggers for behaviour and behaviour change (Petty and Cacioppo 1986; Baumeister et al. 2007). While these are all valid critiques, we would like to discuss less clearly elaborated shortcomings that arise from years of experiences in studying the uptake of technology. To highlight these, we continue to assume situations where individuals are indeed explicitly considering to some degree whether or not to adopt some kind of practice or technology. We first point to the issue of interdependence as an important omission in the thinking about adoption and then propose additional factors and variables that may explain why people do or do not adopt a new behaviour or technology.

\subsubsection{The Issue of Interdependence}

An issue that tends to be insufficiently acknowledged in the individualist behavioural perspective on adoption is that the performance of a specific behaviour is always linked with (and dependent on) the performance of other behaviours (Aarts 2018a). Several types of interdependence can be distinguished, labelled below as vertical, horizontal, intra-individual and time-related interdependencies.

Vertical interdependencies When considering whether or not to adopt a behaviour or technology, people frequently depend on the behaviours of dissimilar others. Farmers, for example, are embedded in several value chains and will consider a new practice in the context of what others in a value chain may do or not do. When considering whether or not to adopt a new crop variety, they may take into account whether or not local traders will actually be interested to collect and buy the produce, whether the agro-dealer will be willing to provide necessary pesticides on 
Table 4.2 Overview of categories of determinants that are seen to influence adoption behaviour (similar terms used instead of 'adoption behaviour' include actual use, usage behaviour, behaviour, adoption)

\begin{tabular}{|c|c|}
\hline $\begin{array}{l}\text { Category of determinants } \\
\text { (Similar terms used in } \\
\text { literature) }\end{array}$ & Description \\
\hline $\begin{array}{l}\text { 1. Intention } \\
\text { (behavioural intention, } \\
\text { intention to use) }\end{array}$ & $\begin{array}{l}\text { In many models, it is assumed that adoption behaviour is preceded } \\
\text { by an overall predisposition to perform the behaviour. This is the } \\
\text { weighed resultant of several other components in this table (notably } \\
2,4 \text { and } 7 \text { ) }\end{array}$ \\
\hline $\begin{array}{l}\text { 2. Attitude } \\
\text { (perceived usefulness, } \\
\text { relative advantage, } \\
\text { attitude towards use) }\end{array}$ & $\begin{array}{l}\text { Intention is supposedly shaped by a variable that relates to an overall } \\
\text { feeling that individuals have towards a behaviour or technology, } \\
\text { which can be positive, negative or neutral. Attitude is seen to arise } \\
\text { from two sub-variables, one relating to knowledge and the other to } \\
\text { values (see 3. and 4.) }\end{array}$ \\
\hline $\begin{array}{l}\text { 3. Knowledge } \\
\text { (behavioural beliefs, } \\
\text { outcome expectation, } \\
\text { performance expectation, } \\
\text { behavioural } \\
\text { consequences, belief } \\
\text { about outcomes) }\end{array}$ & $\begin{array}{l}\text { Several models explicate that the attitudinal component (see 2.) is } \\
\text { influenced by what actors perceive to be the consequences of } \\
\text { adopting the behaviour: 'if I adopt this technology/behaviour, then } \\
\mathrm{X}, \mathrm{Y}, \mathrm{Z} \text { is likely to happen'. In essence, this is about predictive } \\
\text { knowledge and understanding }\end{array}$ \\
\hline $\begin{array}{l}\text { 4. Values } \\
\text { (outcome evaluation, } \\
\text { aspirations, goals) }\end{array}$ & $\begin{array}{l}\text { Several models explicate that the likely consequences of adoption } \\
\text { (see 3.) are weighed against people values, that is, those matters that } \\
\text { they find more or less important in a given context. It is in light of } \\
\text { such values that outcomes are interpreted as positive or negative (see } \\
\text { 2.) }\end{array}$ \\
\hline $\begin{array}{l}\text { 4. Social influence } \\
\text { (subjective norm) }\end{array}$ & $\begin{array}{l}\text { Intention is also seen to be shaped by how individuals perceive the } \\
\text { wishes and norms of relevant others. Social influence is seen to arise } \\
\text { from two sub-variables, one relating to norms and the other to } \\
\text { motivation (see 5. and 6.) }\end{array}$ \\
\hline 5. Normative beliefs & $\begin{array}{l}\text { This sub-component of social influence relates to the perceptions } \\
\text { that individuals have with regard to how relevant others would } \\
\text { evaluate adoption or non-adoption. Would they approve or } \\
\text { disapprove if they would perform specific behaviour? }\end{array}$ \\
\hline 6. Motivation to comply & $\begin{array}{l}\text { This sub-component of social influence relates to whether or not } \\
\text { individuals are inclined to follow what others would like them to do } \\
\text { (see 5.). This involves an evaluation of how important and relevant } \\
\text { the views of others are }\end{array}$ \\
\hline $\begin{array}{l}\text { 7. Ability } \\
\text { (perceived self-efficacy, } \\
\text { perceived behavioural } \\
\text { control, perceived ease of } \\
\text { use, complexity, } \\
\text { facilitating factors, effort } \\
\text { expectancy, barriers) }\end{array}$ & $\begin{array}{l}\text { Many models include one or more variables that relate to whether or } \\
\text { not individuals perceive that performing the behaviour (or adopting } \\
\text { the technology) is easy or difficult in light of their own abilities, } \\
\text { capacities and self-confidence. Similarly, some models refer to the } \\
\text { existence of (real or perceived) external barriers or facilitators that } \\
\text { may enable or disable individuals in performing the behaviour. This } \\
\text { ability component is mostly regarded as a third influence on } \\
\text { intention (see 1.) or as a factor that directly influences adoption } \\
\text { behaviour (thus explaining the frequently observed 'intention- } \\
\text { behaviour' gap) }\end{array}$ \\
\hline
\end{tabular}




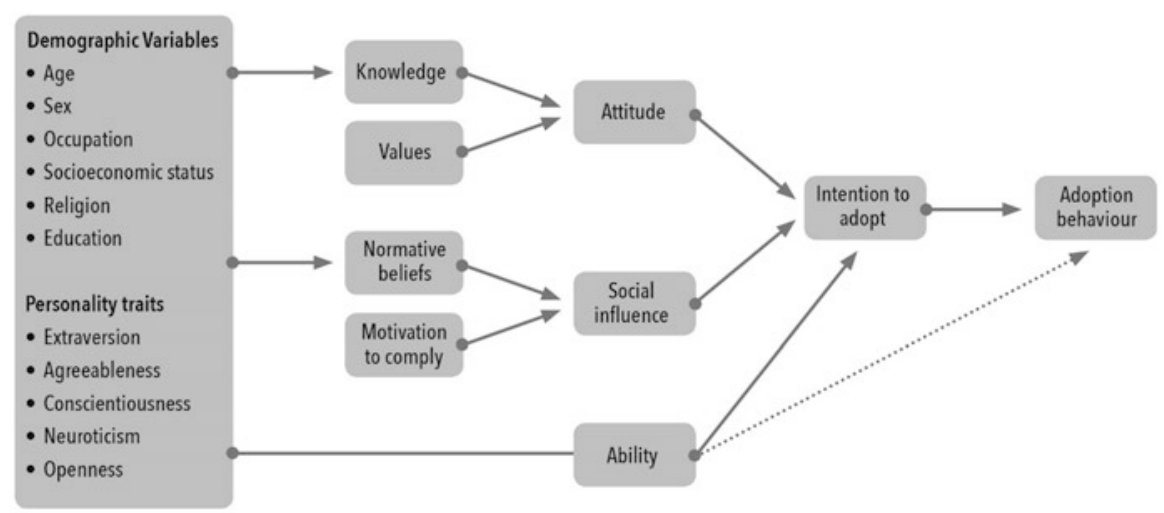

Fig. 4.1 Relationships between main categories of determinants influencing adoption behaviour, as synthesised from various models (see Table 4.2 for related terminology)

credit and/or whether farm labourers will be able to make themselves available at the required time of harvesting. If indeed the variety is new, it is likely to require adapted behaviours of actors along the value chain, which means that adoption of the variety by the farmer is dependent on the simultaneous adoption of complementary behaviours by others in the value chain.

Horizontal interdependencies There are many practices in farming that farmers can only sensibly adopt when other farmers adopt them as well or where adoption is otherwise dependent on the behaviour of other farmers. There exist many crop protection strategies, for example, that are only effective when implemented by the large majority of farmers. If not, sources of infection and disease will continue to exist, rendering adoption useless. Similarly, the growing of new varieties or crops may only be profitable when sufficient farmers in the region join, as buyers may require a certain volume meeting specific quality requirements. Or somewhat differently, farmers in an irrigation scheme or catchment area may only be able to grow a new variety or crop if upstream farmers refrain from using all the water that is available. Again, we see that adoption by one farmer is dependent on the simultaneous adoption of the same or complementary behaviours by other farmers.

Intra-individual interdependencies The adoption of a specific behaviour or technology by an individual often presupposes the acceptance and/or implementation of complementary behaviours by the same individual at more or less the same period in time. Adopting the use of sanitary gloves when milking cows requires several 'preparatory behaviours' such as buying the gloves and instructing family members how to use them. Similarly, adopting a new crop variety may necessitate an earlier or later planting or harvesting date, as well as a different spacing of plants in the field. In other words, in actual practice, 'adoption' involves a plurality of behaviours, and all of these are shaped by the kinds of 'determinants' mentioned in 
Table 4.2. This raises the difficult question of precisely which behaviour one should focus on when aiming to understand why people adopt something or not.

Temporal interdependencies Whether or not people are interested to adopt a behaviour or technology may well depend on adoption decisions that have occurred in the past or on decisions that are anticipated in the future. A farmer who has made considerable investments in chemical spraying equipment may not be interested in switching to biological pest control. Similarly, someone who is anticipating to shift from milk to meat production in the long run may not be prepared to consider new approaches to enhance animal welfare for dairy cattle.

Clearly, in view of these interdependencies, the adoption of a particular behaviour by an individual cannot be understood in isolation from a plurality of behaviours and decisions in the broader environment and context of that person (Leeuwis 2004; Van der Ploeg 1990). Therefore, we propose that adoption must be regarded as a relational issue - as something that takes place within a network of relationships between people in time and space. Since considerations related to interdependencies and relationships are not well represented in the individualist and somewhat rationalist perspective on adoption, we will now explore relevant factors and variables that need to be included in an alternative model for explaining reasons for (non)adoption.

\subsubsection{Adding Complementary Variables}

Issues pertaining to social relations and interdependency may enter into an individual's reasoning in various ways. Below we translate these into several additional perceptual variables.

Trust The insight that people are faced with vertical and horizontal interdependencies when considering adoption can in part be captured by the notion of trust (De Vries et al. 2015), more specifically the expectation that others can be trusted to perform the necessary complementary behaviours and/or provide conducive conditions that enable the adoption of a technology or behaviour. Thus, this variable has connotations of perceived collective ability or perceived environmental effectiveness (Leeuwis 2004). In the context of agriculture, this may relate to whether actors in the agro-support environment or value chain are expected to behave in a conducive manner ('vertical trust') or whether colleagues, household and community members will demonstrate the complementary behaviours on which adoption depends ('horizontal trust'). Another type of trust that may play a role relates to whether the people who are seen to promote the adoption of something are seen to be trustworthy in terms of their expertise, honesty, credibility and legitimacy ('trust in the source'). 
Responsibility In the context of social relationships, people may well consider whether indeed they are and/or should be responsible for addressing the issue at hand. There are many issues in agriculture where such considerations play a role. In the management of pest and diseases, for example, farmers may refuse to adopt certain pest control practices because they regard it as a government responsibility to organise spraying gangs (Dormon 2006). Similarly, farmers may not want to adapt their farming in a manner that saves the environment because they find that others should take their responsibility first.

Social pressure While the dominant social-psychological models typically include a variable related to social influence, the issue of power and enforcement is not very explicit. From a relational perspective, it is important to acknowledge that some people may be seen to have power over others and can impose sanctions or provide rewards to ensure that others behave in a particular way. For example, female farmers may be discouraged from adopting a cash crop because their husbands forbid it and threaten them to reduce their access to land. Alternatively, people may adopt a new variety purely because they expect to face negative consequences from their community leaders if they refuse. Thus, social pressure is a form of social influence that involves dynamics of power, which make it meaningfully different from how individuals perceive the wishes and norms of relevant others (as considered in social-psychological models).

Trade-offs The observation that adoption involves multiple practices and activities further clarifies that adoption may be considered vis-a-vis a range of goals and aspirations. Clearly, people aim at realising a range of goals in life (including in farming). Hereby, different activities and behaviours may serve different goals, but it is also clear that one and the same behaviour may have implications for different values and aspirations. Buying a tractor for ploughing may be economically attractive but may also damage relations with neighbours and/or farm labourers who were involved in ploughing before the arrival of mechanical ploughing. While socialpsychological models involve value-based evaluation of a specific behaviour, it is less clear and explicit that adoption normally involves many behaviours and multiple values at the same time, leading to the likelihood of trade-offs, that is, situations where adoption works out positively for some goals and negatively for others, resulting in the need to make choices and accept certain trade-offs. Different types of goals and aspirations may play a role in the consideration of trade-offs, including economic goals (e.g. high profit or stable cash flow), technical goals (e.g. high milk yield or low water run-off), cultural goals (e.g. showing respect for life), relational goals (e.g. maintaining good relations with neighbours), emotional goals (e.g. safeguarding peace of mind) or ethical aspirations (e.g. ensuring fair and equitable outcomes). The balancing and weighing of multiple perceived outcomes and goal orientations deserve to be made more explicit in models to explain adoption.

Identity It is important to consider that the salient identity that people have or take on when considering something may differ according to the relational setting. 
People tend to have several roles and identities (e.g. be a consumer, a producer, entrepreneur, a father, a husband, a citizen), and they may reason and think differently in different capacities. For example, as a citizen, someone may be all in favour of sustainable agriculture and vote for a green party that proposes a tax on meat or fertiliser, but as a consumer, the same person may have different considerations and buy the cheapest meat available, while as a parent he/she may insist on buying the most expensive meat when their grown-up children come home for dinner. From the perspective of an outsider, such behaviours may be regarded as 'inconsistent', but at the same time, one could argue that they are consistent with the salient identity that is evoked by a certain interaction setting. Thus, the salient identity can be seen to shape the kinds of knowledge, values and social influences that are taken into account when deciding to adopt something or not. Arguably, identity can be important in another way as well, namely, an important motivator for action in specific situations. When people feel that their identity is threatened or treated disrespectfully (e.g. their religious, national or racial identity), they may respond strongly. In this sense too, identity may play a role in adoption of technologies or behaviours. For example, people may resist re-allocation of land in the context of a land consolidation or resettlement scheme because they feel it undermines their identity as landowners who have been custodians of the land for many generations.

Risk and uncertainty The existence of numerous interdependencies in relation to adoption only amplifies and underscores that people may well experience uncertainties or risks in relation to several of the variables discussed so far. They may actually wonder what the consequences of one practice may imply for other practices and outcomes or have doubts about how relevant others might respond to their adoption behaviour. Clearly, people are not all knowing about the world around them and may neither be fully convinced about the adequacy of their beliefs, the level of their capacities and/or the importance of competing aspirations. It is likely that such uncertainties and/or risk perceptions have an impact on people who actively consider the adoption of something, but this is not well represented in the dominant models.

Institutions While the complementary variables mentioned so far relate to people's mindsets and mental considerations, it is useful to introduce another type of concept from a rather different academic tradition: the idea that practices or behaviours are shaped by 'institutions'. Institutions can be seen as the formal and inform rules and arrangements to which people orient themselves in their (inter)action (North 1990). We may think of the regulations that govern interactions in markets and value chains, the informal standards and norms regarding appropriate social behaviour, the formal legal rules that people take into account when deciding how to deal with a conflict and/or the procedures that are in place to arrive at democratic decisionmaking. Clearly, such rules and arrangements (in some literatures called 'structures' or 'regimes') can have an important influence on what people do or do not do. As mentioned, institutional explanations of behaviour stem from a completely different tradition than social-psychological and individualist explanations but certainly 
merit attention when discussing interdependencies in the context of adoption. In fact, we see that more recent perspectives on innovation than the traditional view described by Rogers (1995) pay considerable attention to issues pertaining to institutions. Currently dominant institutional configurations (or regimes) are often regarded as an obstacle to change and innovation (Geels and Schot 2007); for example, prevailing flat price setting arrangements in the value chain may obstruct the use of quality-enhancing technologies by farmers. At the same time, the existence of such obstacles leads to a call for 'institutional innovation' as an integral component of socio-technical transformation, in this example, the introduction of quality control and price differentiation arrangements to enable farmers to invest in qualityenhancing practices and technologies (Leeuwis 2013). Moreover, innovation processes themselves are seen to be influenced by institutional set-ups that govern interaction between actors in an 'innovation system' or 'innovation ecology' (Hall et al. 2007; Leeuwis et al. 2017), for example, the reward systems in universities may hinder conducive interaction between researchers from different disciplines and/or prevent scholar to engage actively with societal stakeholders.

\subsection{Linking Institutional Explanations to Individual Explanations}

The question then is how institutional explanations and more individual considerations relate to each other and how the former may be taken into account in a model that complements (but also still builds on) an individualist perspective. We would propose that institutions tend to create resources and (dis)incentives that may enter people's considerations in several ways.

Clearly, rules and arrangements can be seen as shaping the ways in which social influence and social pressure may be exerted or experienced. For example, the standards and rules implied in certification and pricing systems may be used by traders as a leverage to negotiate prices and/or provide (or deny) access to certain market channels and thus operate as an (dis)incentive for farmers to produce in a certain manner. At the same time, such (dis)incentives are likely to affect people's aspirations and alter the balance in assessing trade-offs between different goals. Moreover, the existence of community by-laws and accompanying control and sanctioning systems may affect the extent to which farmers trust their neighbours in adhering to preventive measures against diseases. Institutions may also shape the knowledge and beliefs that people have about the world and/or about the outcomes of specific behaviours. The belonging to certain scientific disciplines, religious groups or cultural communities, for example, impinges on how people consider their relation with nature (Douglas 1970) and also on agricultural knowledge and beliefs. Organic farmers, for example, tend to have a very different belief system regarding the control of diseases and/or the management of soil fertility than so-called 'regular' 
farmers. Similarly, such cultural belongings and identities may relate to what people feel responsible for and what not.

Thus, in a setting where multiple people interact and depend on each other, institutions can be seen to orient actors' ways of thinking, that is, their beliefs, experienced influence or pressure, aspirations, trust, risk perceptions, abilities, responsibilities, etc. This should not be interpreted in a deterministic manner as actors can have considerable agency and space for manoeuvre (Long 1990; Giddens 1984) to interpret what rules and arrangements apply to the situation at hand.

Figure 4.2 captures what we have discussed so far:

Figure 4.2 provides what one could call a 'sociologically enhanced' overview of the reasons that people may have for adopting or rejecting an innovation (consisting of a package of behaviours A, B, C). When compared with Fig. 4.1, it includes a range of additional relational variables and considerations that have to do with how other people are looked at: whether they exert power and pressure, whether they can be trusted to (be willing and able to) perform complementary behaviours and/or whether proposed responsibilities and identities are meaningful to the situation. The figure also captures the role of salient identities and institutions as well as the role of time; it makes clear that previous behaviours and experiences play a role and that the adoption of a set of new practices generates responses in the agro-ecological and social world that are being interpreted, leading to changes in people's 'mindset'. For example, growing a new variety may go along with a variety of experiences which are likely to influence peoples' reasoning with regard to future activities: Did it grow well?, Was it resistant to diseases?, How much effort was needed?, Was I able to sell the crop against a good price?, Did my family members like the taste?, etc. Once behaviours associated with an innovation have been adopted (and often adapted), they are likely to become a routine or habit, that is, a regular practice that is no longer actively deliberated every time it is enacted. This is why the concept of 'intention' has been omitted from Fig. 4.2; while behaviours may continue to be rationalised ex-post (e.g. when asked about in an interview setting), it is not accurate to assume that everything people do is preceded by careful deliberation. However, at some point in time, routines may become subject to active reflection again, for example, when a relatively stable situation is disrupted and/or when longer-term negative consequences become visible.

\subsection{An Interactional View}

Whereas Fig. 4.2 still gravitates towards an individualist perspective as it includes only one relatively isolated 'mindset', Fig. 4.3 is an attempt to correct that to some degree.

While Fig. 4.3 refers to the same parameters as Fig. 4.2, it highlights that adoption occurs in an interactional context where several people (in reality more than two) depend on each other in their performance. This interaction evokes salient identities of participants and is oriented by the formal and informal institutions that 


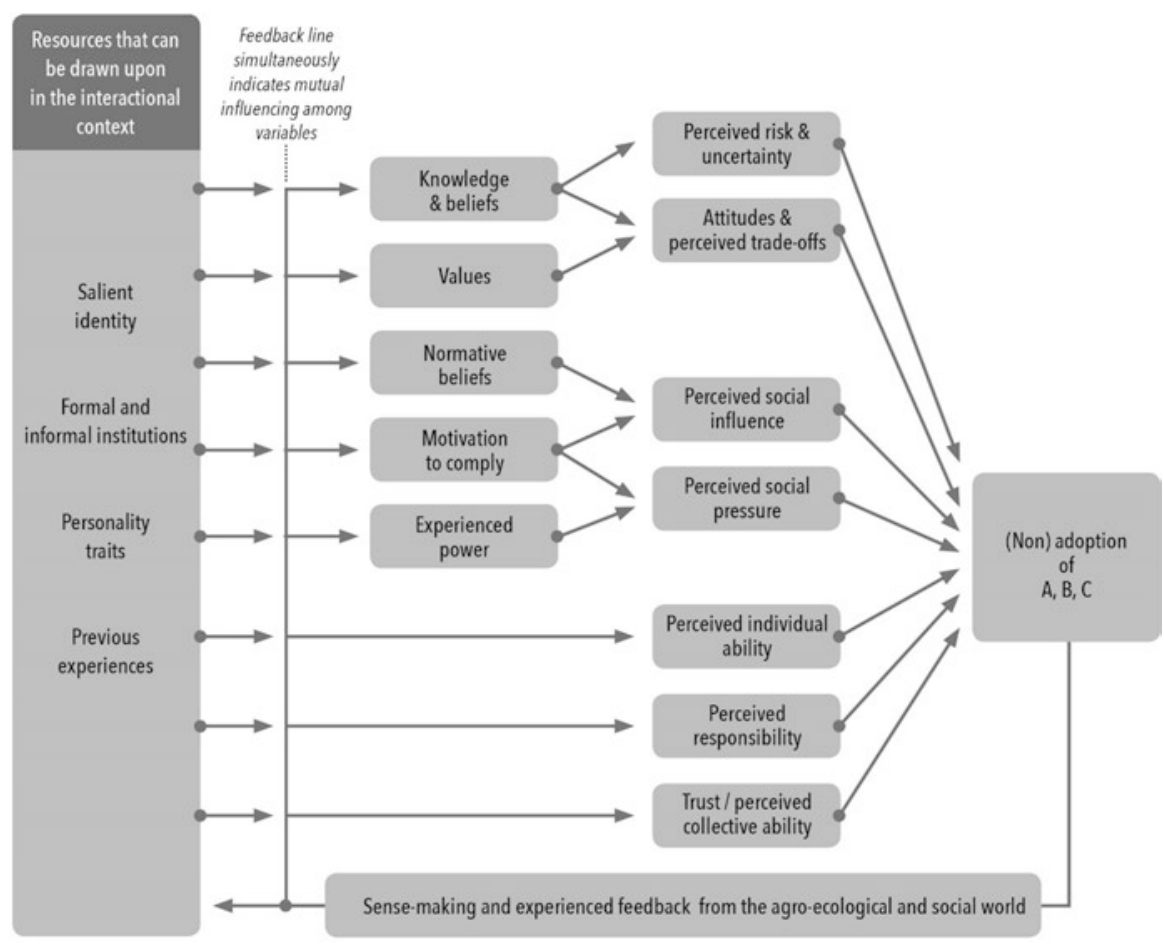

Fig. 4.2 Reasons for (non)adoption: complementing individual determinants with variables arising from interdependence and institutional influences

actors draw upon. The 'mindsets' of the actors (their 'reasons for (non)adoption', see Fig. 4.2) are influenced by the exchange that takes place, by the elements in the institutional setting that are deemed relevant as well as by contextual conditions, personality traits and previous experiences. At any point in time, the participants are likely to have meaningfully different 'mindsets' and/or priorities in their reasoning, which are bound to change and evolve during the process. As an outcome of the interaction, the people involved may or may not adopt complementary practices (A, $\mathrm{B}, \mathrm{C}$ and $\mathrm{X}, \mathrm{Y}, \mathrm{Z}$ ), or enable or constrain each other to move in a given direction.

The image makes clear that in order to move towards the adoption of a specific package of interrelated practices (say prevention of diseases through integrated pest management practices in a community), the actors involved must somehow develop 'mindsets' that are congruent with each other. This may be in the form of jointly agreed upon rules or by-laws (institutions), overlapping aspirations (values), shared understandings of what will happen if A, B, C and X, Y, Z are performed (knowledge and beliefs) and mutual recognition of the rewards and sanctions that will be applied (social pressure). Arriving at such mutual adjustment and understanding involves different (or at least additional) processes than the individual decisionmaking processes portrayed in Table 4.1. As argued and elaborated elsewhere 


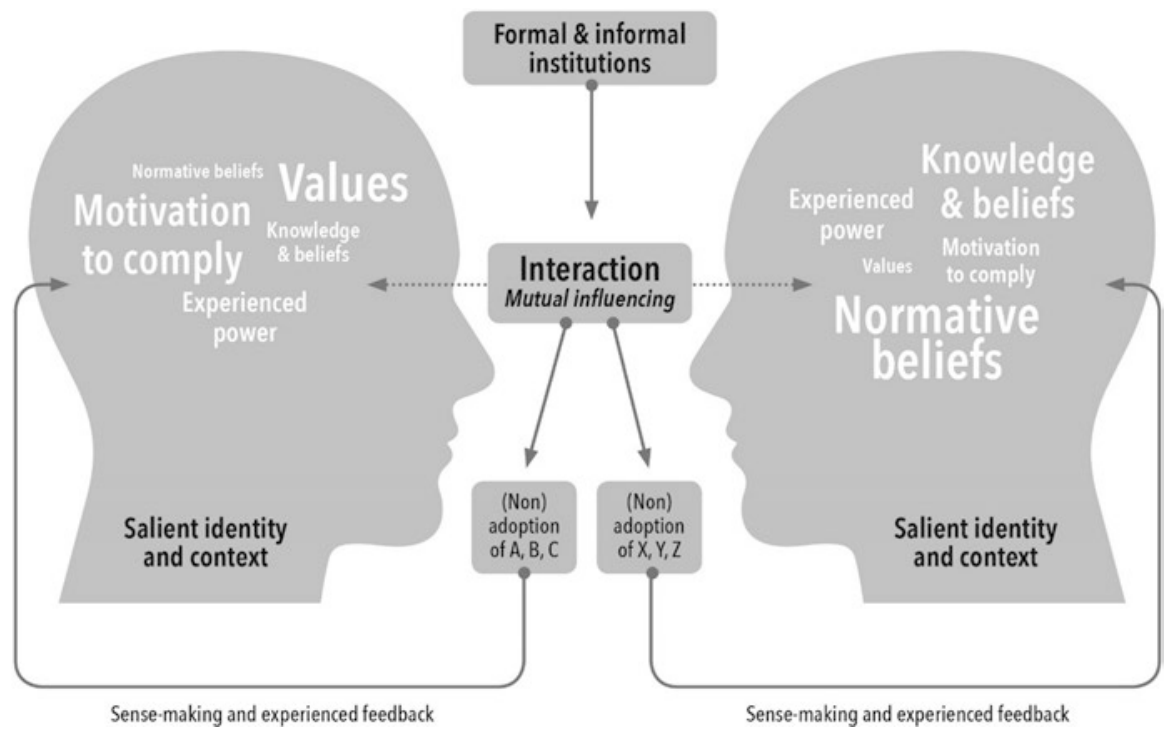

Fig. 4.3 An interactional view of reasons for (non)adoption

(Leeuwis 2004; Leeuwis and Aarts 2011; Aarts 2018b), mutual adjustment typically involves processes of social learning, negotiation and conflict resolution. Such processes may be facilitated by 'innovation intermediaries' that play broader roles than providing individual advisory services and/or applying persuasive strategies geared towards changing individual behaviour (see for details Leeuwis 2004; Klerkx and Leeuwis 2008; Klerkx et al. 2009).

\subsection{Implications for Development Practice: Rethinking Scaling and Information Provision Through ICT4Ag}

As indicated at the start, fostering agricultural development in one direction or another always involves changes in human practices and hence the 'adoption' of new technological and/or social-organisational behaviours. From the perspective of development practitioners, it is relevant to ask what the practical implications are of our 'interactional' and 'sociologically enhanced' perspective on 'reasons for (non) adoption'. Below, we will apply our perspective to two topical issues that actors in the field of agricultural development tend to struggle with in different contexts. The first issue involves the idea of achieving development impact through the 'scaling' of innovations, and the second issue relates to information provision through 'ICT4Ag' (information and communication technology for agriculture) as a means of supporting processes of adoption and scaling. 


\subsubsection{Sharpening Our Thinking About 'Scaling'}

While the term 'scaling' has some broader connotations (Wigboldus 2018; Wigboldus et al. 2016), it is often used in a way that resembles the older terminology of 'adoption and diffusion of innovations' as used by Rogers (1962). Both terminologies often express a normative desire to ensure that something that is considered to be good and desirable spreads across a greater number of users and/or across a larger geographical area, in order to achieve some kind of societal impact. 'Scaling' is seen as a critically important process and frequently also as an enormous challenge. Our model of 'reasons for (non)adoption' may help in several ways to sharpen our thinking about 'scaling'.

The plurality of scaling: thinking in terms of assemblages The 'reasons for (non) adoption' model is a response to the existence of several types of interdependencies in a development setting (see above). These interdependencies imply that one cannot usefully consider the scaling of one particular practice in isolation from other practices, including practices that are performed by other people than the originally perceived 'users'. Similarly, the 'upscaling' of one practice is likely to require the 'downscaling' of other practices that are being replaced or affected. Hence, it is important to think about scaling in terms of multiple practices in an assemblage that are simultaneously scaling up or down (Leeuwis and Wigboldus 2017; Sartas et al. 2019). Identifying the interdependent practices in a network of interdependent stakeholders (and in time) provides useful insights in the complexity of a particular scaling ambition (see Fig. 4.4 and Sartas et al. 2019; Sartas et al. 2020).

Targeting 'bottleneck' or 'leverage' practices as entry points Having insight in an assemblage of interdependent practices begs the critically important question of which practice(s) could or should be the focus of attention in a development effort (Sartas et al. 2019). While the original entry point might be the wish to 'scale' a drought-resistant variety, a consideration of the broader assemblage of practices involved may well lead to the identification of more relevant entry points for intervention. The use of the variety by farmers may, for example, be constrained by prevailing policies that prevent the release or distribution of the variety, thus shifting the attention to interventions that may help to overcome such policy bottlenecks rather than simply promote the variety. Alternatively, one may conclude that the use of the variety can be leveraged by the creation of specific price incentives offered by a dominant trader or wholesaler. In a complex environment of interrelated practices, it is an illusion to think that one can bring about change by focussing on one particular issue or practice, while at the same time, it is unrealistic and inefficient to target interventions on everything that matters. Thus, interventionists need to somehow identify the critical interdependencies and leverages in the system in order to develop an effective scaling strategy (Sartas et al. 2019; Vellema and Leeuwis 2019).

Diagnosing with the help of the model Finding the leverage or bottleneck practices requires an understanding of stakeholders' (interactional) rationale in relation 


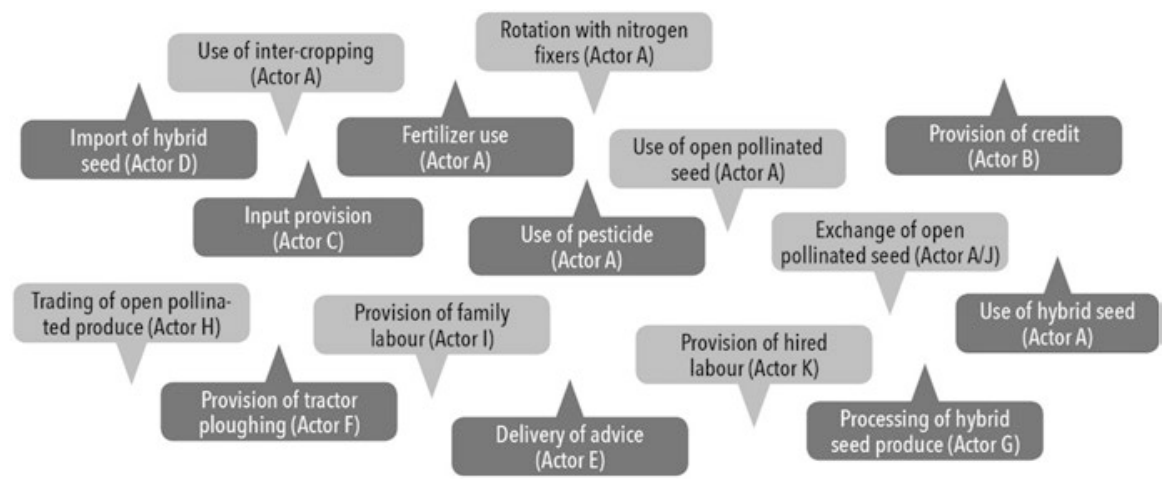

Fig. 4.4 Fictitious example of multiple practices scaling 'up' and 'down' simultaneously in an assemblage

to existing and/or alternative practices. In other words, what are the reasons that underpin current practices and interaction patterns and/or what are the reasons that actors have for rejecting alternative practices and courses of action? The 'reasons for (non)adoption' model (Figs. 4.2 and 4.3) offers several entry points of investigating and diagnosing these.

First, the model offers a more elaborate overview of relevant variables than social-psychological models, which can be used to describe and analyse people's rationale. For example, if one wants to understand why farmers refuse to spray against a disease, one may consider how this relates to their knowledge (how do they understand the disease dynamics?), their feelings of responsibility (do they feel responsible for combating the disease?), their values (how important is the crop for them?), the social influence or social pressures experienced (what do others expect and what sanctions or incentives are in place?), their trust in others (are farmers confident that others will spray as well and/or that the agro-dealer sells the right chemicals?) and their individual abilities (are farmers confident that they have the right skills and equipment for spraying and/or can they afford to obtain these?). Disentangling people's rationale in relation to several practices in an assemblage helps to understand what the most important bottlenecks or leverages may be. Simultaneously, this offers entry points for intervention: if farmers refuse to spray because they do not understand the dynamics of the disease, then it makes sense to invest in interventions that foster awareness raising and learning. However, if farmers do not feel responsible or do not trust that their neighbours will also spray, then other types of strategies will have to be considered.

A second entry point for diagnostic analyses offered by the model is to focus on the formal and informal institutions that orient people's considerations and ways of thinking. When the purpose is to develop a scaling strategy, such analysis of people's rationales and underlying institutions needs to be combined with an assessment of which critically bottlenecks and leverages may be(come) amenable to change and what types of interventions (ranging from persuasive campaigns to 
participatory design in a multi-stakeholder process) may be conducive to achieving this (Sartas et al. 2019). As already hinted at, the realisation that scaling involves many interdependencies and a plurality of practices and stakeholders implies that approaches that allow for multi-stakeholder learning and negotiation are likely to be relevant in many instances (Leeuwis and Aarts 2011).

Responsible scaling Thinking in terms of interdependent practices between stakeholders also highlights that scaling a particular practice may trigger and/or result in the scaling of other practices and phenomena that were not initially considered. Thus, new practices may yield positive or negative consequences for those directly involved and also generate outcomes that occur at other levels of aggregation. The use of a new drought-resistant variety may, for example, make households dependent on credit for buying seeds, which - in case of high interest rates - may negatively affect households' resilience or ability to pay school fees. Similarly, the application of new oil palm production systems at a large scale may have negative consequences for biodiversity in a region, or put farmers in another region out of business. Investigating and anticipating these kinds of interrelations is part and parcel of a broader approach that Wigboldus has labelled 'responsible scaling' (Wigboldus 2018) - the careful consideration of possible positive and negative consequences of scaling with regard to diverse societal values and categories of people, as well as principles of ethics and democracy. Thinking in terms of interdependencies between practices is a useful way of starting such a process (see for more elaboration and guidance Wigboldus and Brouwers 2016).

The kind of thinking presented here about scaling has been further translated into tools and methods that may support the development of scaling strategies elsewhere (Sartas et al. 2019).

\subsubsection{Rethinking Information Provision Through ICT4Ag: The Example of Disease Control}

The early work of Rogers (1962) and Van den Ban (1963) already highlighted the importance of communication and information provision (see Table 1) in supporting adoption and scaling processes. In the current age of enhanced mobile phone and internet connectivity in developing countries (Dey et al. 2016; De Bruijn and Van Dijk 2012), there is a lot of attention to how digital ICT platforms may be leveraged to enhance scaling. Therefore, a relevant question is how our 'interactional' and 'sociologically enhanced' understanding of 'reasons for (non)adoption' may impinge on communicative intervention and information provision through ICT (or other media).

First of all, it is relevant to note that the individualist and rationalist perspective on adoption has greatly inspired and influenced communicative interventions geared towards agricultural development, as exemplified in the practice of agricultural 
extension (Van den Ban and Hawkins 1996). Typically, agricultural extension handbooks and extension professionals identify strongly with the idea that individuals need to be provided with relevant information that guides them through the adoption process, that is, provision of information about problems, solutions, pros and cons associated with alternative options, etc. geared largely towards changing people's beliefs and attitudes (see Table 4.2) in favour of specific behaviours. Classically, such information was communicated through a mix of mass media and interpersonal media. While the media may have changed, it is interesting to note that ICT applications in agricultural extension may still tend towards provision of similar kinds of information to farmers. Recent inventories of ICT4Ag indicate that extension organisations use virtual platforms to enhance organisational processes through better registration of farmers, recording of activities and internal reporting and also to provide farmers with up-to-date weather and market information (Munthali et al. 2018). When it comes to technical advice that is explicitly geared towards influencing adoption, we see that ICTs are frequently used to provide information about 'best practices' through, e.g. repositories, voice messages, text messages, video clips and alerts. While the channel and speed through which information is provided may have meaningfully changed, such information arguably is still directed at individual farmers and contains similar messages as in traditional extension regarding the existence of problems and solutions and the pros and cons of different courses of action.

If indeed ICT4Ag continues to be geared towards influencing beliefs, attitudes and individual adoption decisions, it is likely to fall short in similar ways as preexisting forms of decision support in that these do not directly address interdependencies between people and practices. Thus, it is worthwhile to think about what ICT4Ag might have to offer in terms of supporting processes of collective decisionmaking on farmer-level agricultural issues. Phrased differently, how may ICT4Ag help to anticipate influential interactional processes, and be used to shape the more relational variables in our 'reasons for (non)adoption' model, including social pressure, power, trust, responsibility, salient identity and institutions?

To explore this further, it may help to think of an important farmer-level issue in which interdependencies among farmers tend to play an important role: the prevention and control of pests and diseases. There exist numerous plant diseases whereby the efficacy of control measures on one farm depends on what other farmers in the vicinity do. If farmers in the immediate environment do not take sufficient preventive or curative measures (e.g. disinfect tools, prevent water run-off, remove and burn diseased plants, apply spraying at the right time, install insect traps, buy clean planting materials, etc.), it becomes almost futile for a farmer to invest in disease control on his or her own, since the field will continue to become infected by the disease. In such cases, diseases can be seen as a 'public bad', while effective disease control strategies can be regarded as a 'public good' that is only created if sufficient farmers contribute to it (Cieslik et al. 2018; Leeuwis et al. 2018). In these kinds of situations, it is clearly insufficient to only provide individuals with technical advise on how to prevent and control the disease; even if farmers come to belief that such measures are likely to be effective and develop a positive attitude towards them, 
they are unlikely to perform them unless they are reasonably sure that their neighbours will take proper action as well.

In connection with these kinds of situations, Ostrom $(1990,2009)$ has identified several communicative and informational conditions and strategies related to the interaction between interdependent actors that are conducive to creating a "public good' (e.g. an effective community-based disease management strategy). Below, we briefly discuss these conditions and how they link to our 'reasons for (non)adoption' model and the possibilities of ICT4Ag.

Typically, the effective maintenance of a common pool resource and/or the creation of a public good requires the existence of certain rules (institutions) with regard to how people in a community of actors should behave. In relation to pest and disease management, such rules could be 'to remove and burn diseased plants as soon as possible', to 'build ditches around diseased fields to prevent infection through run-off water', to 'apply preventive spraying after the first rains have passed' and/or 'to make a monthly contribution to cover maintenance costs of collective spraying equipment'. Ostrom $(1990,2009)$ concludes that in order for such rules to be effective, it is important that most individuals in the community are able to participate in making and modifying them. Clearly, this requires intensive communication between interdependent actors in the community. Similarly, fostering adherence to such rules depends on the availability of various kinds of information. According to Ostrom, members of the community need an up-to-date information about the condition of the resource that is relevant and actionable in view of the prevailing rules, in this case, information about the agro-ecological conditions of the field and the actual presence of the disease. In addition, community members are more likely to conform to the rules if they have information about the behaviour of others on which they depend, for example, information with regard to whether or not others are fulfilling their obligations or not and whether or not sanctioning systems operate effectively. Clearly, the generation and distribution of such information requires the operation of a monitoring system that captures both agro-ecological conditions and human behaviour and makes them available to those belonging to the community.

Clearly, the kinds of communicative and informational functions mentioned above can potentially be supported by ICT. Social media applications may, for example, support interaction within a community of actors during the process of designing rules and even help enlarge the boundaries of effective community formation and identity building (Cieslik et al. 2018; Bennett and Segerberg 2012). Similarly, mobile phones can serve to record, report and process decentralised observations as part of a community-based monitoring system for pest and disease management and help to share such information with participating farmers. In this manner, communicative and informational services may help to foster conducive conditions for collective action in response to agricultural pests and diseases. It must be noted that such types of ICT applications would differ markedly from those oriented towards disseminating 'best practices' and/or persuading individual farmers to adopt them. Rather than focussing on influencing 'determinants' for individual behaviour (e.g. knowledge, attitudes, ability), they are geared towards supporting 
collective identity formation, design of institutions, maintenance of trust and the effective use of power and sanctioning systems in a community of actors. Thus, our 'interactional' and 'sociologically enhanced' understanding of 'reasons for (non) adoption' helps us to imagine different kinds of ICT4Ag applications than those that just provide regular extension services through a different medium.

\subsection{Concluding Remarks}

While recent critiques of the notion of adoption emphasise the shortcomings of the technocentric and binary thinking that is often implied, this chapter has focussed on the limitations in dominant thinking about the process side of adoption and has broadened the scope by providing an interactional perspective. For a long time, adoption has been portrayed as a largely individual process that could be understood and influenced with the help of social-psychological models. We have argued that this kind of thinking ignores the existence and importance of vertical, horizontal, intra-individual and time-related interdependencies between practices, leading to the conclusion that in many instances, adoption must be regarded as a collective rather than an individual process. We have indicated how interdependencies may enter into an individual's reasoning about adoption in various ways and have translated this into several additional variables that need to be considered when the aim is to explain adoption and behaviour change or the lack of it. Consideration of these variables has led us to develop an 'interactional' and 'sociologically enhanced' model for understanding 'reasons for (non)adoption'. Subsequently, we have explored the practical implications of this mode of thinking by linking them to topical issues such as 'scaling' and the use 'ICT4Ag' in stimulating adoption. This exploration reveals that we can sharpen our thinking about scaling considerably by realising that scaling always involves an assemblage of different interdependent practices across a network of stakeholders in time and space, which necessitates critical thinking about points of leverage and issues of responsibility. Similarly, our exploration of the role that ICT4AG may play in the management of agricultural diseases has revealed that the enhanced model for understanding reasons for (non) adoption solicits the design of novel kinds of ICT applications and services that may support the creation of conducive conditions for collective action. Thus, moving beyond individualist conceptualisations of adoption not only represents a theoretical advance but also helps us to re-imagine and re-orient the kinds of interventions needed to shape adoption processes in support of realising a desired future.

Acknowledgements This research was undertaken as part of, and funded by, the CGIAR Research Program on Roots, Tubers and Bananas (RTB) and supported by CGIAR Trust Fund contributors as well as by NWO and Wageningen University. 


\section{References}

Aarts MNC (2018a) Dynamics and dependence in socio-ecological interactions. Inaugural address. Radboud University Nijmegen, Nijmegen

Aarts MNC (2018b) Boundary spanning for strategic communication: towards an interactional and dynamic perspective. In: Heath RL, Johansen W (eds). The international encyclopedia of strategic communication, Boston. Wiley - Blackwell Publishers, pp 91-96

Ajzen I (1985) From intentions to actions: a theory of planned behavior. In: Kuhl J, Beckmann J (eds) Action control: from cognition to behavior. Springer, New York, pp 11-39

Ajzen I (1991) The theory of planned behavior. Organization behavior and human decision processes. pp 179-211

Baumeister R, Vohs K, Tice D (2007) The strength model of self-control. Curr Dir Psychol Sci 16(6):351-355

Bennett WL, Segerberg A (2012) The logic of connective action. Inf Commun Soc 15(5):739-768

Cieslik KJ, Leeuwis C, Dewulf ARPJ, Lie R, Werners SE, van Wessel M, Feindt P, Struik PC (2018) Addressing socio-ecological development challenges in the digital age : exploring the potential of environmental virtual observatories for connective action (EVOCA). NJAS Wageningen J Life Sci 86-87:2-11

Davis FD, Bogozzi R, Warshaw PR (1989) User acceptance of computer technology: a comparison of two theoretical models. Manag Sci 35:982-1003

De Bruijn ME, Van Dijk R (2012) Connecting and change in African societies: examples of 'ethnographies of linking' in anthropology. Anthropologica 54:45-59

De Vries JR, Aarts N, Lokhorst AM, Beunen R, Oude Munnink J (2015) Trust-related dynamics in contested land use. A longitudinal study towards trust and distrust in intergroup conflicts in the Baviaanskloof, South Africa. J Forest Policy Econ 50:302-310

Dey B, Sorour K, Filieri R (2016) ICTs in developing countries: research, practices and policy implications. Palgrave Macmillan, New York and London

Dormon ENA (2006) From a technology focus to innovation development : the management of cocoa pests and diseases in Ghana. PhD dissertation, Wageningen University

Douglas M (1970) Natural symbols. Explorations in cosmology. Barrie and Rockliff/Cresset Press, London

Fishbein M, Ajzen I (1975) Belief, attitude, intention, and behavior: an introduction to theory and research. Addison-Wesley Pub. Co., Reading/Don Mills

Geels FW, Schot JW (2007) Typology of sociotechnical transition pathways. Res Policy 36(3):399-417

Giddens A (1984) The constitution of society: outline of the theory of structuration. Polity Press, Cambridge

Glover D, Sumberg J, Andersson JA (2016) The adoption problem; or why we still understand so little about technological change in African agriculture. Outlook Agric 45(1):3-6

Hall A, Clark N, Naik G (2007) Institutional change and innovation capacity: contrasting experiences of promoting small scale irrigation technology in South Asia. Int J Technol Manag Sustain Dev 6(2):77-101

Kahneman D (2011) Thinking, fast and slow. Penguin Books, London

Klerkx L, Leeuwis C (2008) Matching demand and supply in the agricultural knowledge infrastructure: experiences with innovation intermediaries. Food Policy 33(3):260-276

Klerkx LWA, Hall A, Leeuwis C (2009) Strengthening agricultural innovation capacity: are innovation brokers the answer? Int J Agric Res Gov Ecology 8(5-6):409-438

Leeuwis C (with contributions by A. Van den Ban) (2004). Communication for rural innovation. Rethinking agricultural extension. Blackwell Science/CTA, Oxford/Wageningen, $412 \mathrm{p}$

Leeuwis C (2013) Coupled performance and change-in-the-making. Inaugural lecture. Wageningen University, Wageningen

Leeuwis C, Aarts N (2011) Rethinking communication in innovation processes: creating space for change in complex systems. J Agric Educ Extension 17(1):21-36 
Leeuwis C, Wigboldus S (2017) What kinds of 'systems' are we dealing with? Implications for systems research and scaling. In: Öborn I, Vanlauwe B, Phillips M, Thomas R, Brooijmans W, Atta-Krah K (eds) Sustainable intensification in smallholder agriculture. an integrated systems research approach., Earthscan food and agriculture series. London and New York. Routledge Taylor \& Francis Group, pp 319-333

Leeuwis C, Schut M, Klerkx L (2017) Systems research in the CGIAR as an arena of struggle: competing discourses on the embedding of research in development. In: Sumberg J, Andersson J, Thompson J (eds) Agronomy for development: the politics of knowledge in agricultural research. Routledge, pp 59-78

Leeuwis C, Cieslik KJ, Aarts MNC, Dewulf ARPJ, Ludwig F, Werners SE, Struik PC (2018) Reflections on the potential of virtual citizen science platforms to address collective action challenges : lessons and implications for future research. NJAS Wageningen J Life Sci 86-87:146-157

Loevinsohn M, Sumberg J, Diagne A (2012) Under what circumstances and conditions does adoption of technology result in increased agricultural productivity? Protocol, EPPI Centre, Social Science Research Unit, Institute of Education, University of London, London

Loevinsohn M, Sumberg M, Diagne A, Whitfield S (2013) Under what circumstances and conditions does adoption of technology result in increased agricultural productivity? A systematic review. IDS, Brighton

Long N (1990) From paradigm lost to paradigm regained? The case for an actor-oriented sociology of development. Eur Rev Latin Am Caribbean Stud 49:3-32

Munthali N, Leeuwis C, van Paassen A, Lie R, Asare R, van Lammeren R, Schut M (2018) Innovation intermediation in a digital age : comparing public and private new-ICT platforms for agricultural extension in Ghana. NJAS Wageningen J Life Sci 86-87:64-76

North DC (1990) Institutions, institutional change and economic performance. Cambridge University Press, Cambridge

Ostrom E (1990) Governing the commons: the evolution of institutions for collective action. Cambridge University Press, Cambridge

Ostrom E (2009) Beyond markets and states: polycentric governance of complex economic systems. Prize lecture, December 8, 2009. Workshop in Political Theory and Policy Analysis, Indiana University, Bloomington, IN 47408, and Center for the Study of Institutional Diversity, Arizona State University, Tempe

Petty RE, Cacioppo JT (1986) The elaboration likelihood model of persuasion. In: Berkowitz L (ed) Advances in experimental social psychology, 19. Academic Press, New York, pp 123-205

Rana NP, Dwivedi YK (2015) Citizen's adoption of an e-government system: validating extended social cognitive theory (SCT). Gov Inf Q 32(2):172-181

Rogers EM (1962) Diffusion of innovations, 1st edn. Free Press, New York

Rogers EM (1995) Diffusion of innovations, 4th edn. Free Press, New York

Sartas M, Leeuwis C, van Schagen B, Velasco C, Thiele G, Proietti C, Schut M (2019) Scaling readiness quick guide. Concepts and Practices of Scaling Readiness. CGIAR Research Program on Roots, Tubers and Bananas (RTB). July 2019. Available at www.scalingreadiness.org

Sartas M, Schut M, Thiele G, Proietti C, Leeuwis C (2020) Scaling Readiness: Science and practice of an approach to enhance impact or research for development. Agricultural Systems 183

Taherdoost H (2018) A review of technology acceptance and adoption models and theories. Procedia Manufacturing 22:960-967

Van den Ban AW (1963) Boer en landbouwvoorlichting: De communicatie van nieuwe landbouwmethoden. Pudoc, Wageningen

Van den Ban AW, Hawkins HS (1996) Agricultural extension, 2nd edn. Blackwell Science, Oxford

Van der Ploeg JD (1990) Labor, markets, and agricultural production. Westview Press, Boulder

Vellema S, Leeuwis C (2019) Contextualising scaling. Shifting from individual choices to generative processes in networks. Discussion note prepared for the CCAFS NWO-GCP4 Mid-Term Workshop, held in Addis Ababa, June 12-14, 2019 
Venkatesh V, Davis FD (2000) A theoretical extension of the technology acceptance model: four longitudinal field studies. Manag Sci 46(2):186-204

Venkatesh V, Morris MG, Davis FD, Davis GB (2003) User acceptance of information technology: toward a unified view. MIS Q 27:425-478

West RL, Turner LH (2010) Uses and gratifications theory. In: West RL, Turner LH (eds) Introducing communication theory: analysis and application. McGraw-Hill, Boston, pp 392-409

Wigboldus S (2018) To scale, or not to scale - that is not the only question: rethinking the idea and practice of scaling innovations for development and progress. $\mathrm{PhD}$ dissertation, Wageningen University, London and New York

Wigboldus S, with Brouwers J (2016). Using a theory of scaling to guide decision making. Towards a structured approach to support responsible scaling of innovations in the context of agrifood systems. Wageningen University and Research, Wageningen

Wigboldus S, Klerkx L, Leeuwis C, Schut M, Muilerman S, Jochemsen H (2016) Systemic perspectives on scaling agricultural innovations. A review. Agron Sustain Dev 36

Open Access This chapter is licensed under the terms of the Creative Commons Attribution 4.0 International License (http://creativecommons.org/licenses/by/4.0/), which permits use, sharing, adaptation, distribution and reproduction in any medium or format, as long as you give appropriate credit to the original author(s) and the source, provide a link to the Creative Commons license and indicate if changes were made.

The images or other third party material in this chapter are included in the chapter's Creative Commons license, unless indicated otherwise in a credit line to the material. If material is not included in the chapter's Creative Commons license and your intended use is not permitted by statutory regulation or exceeds the permitted use, you will need to obtain permission directly from the copyright holder.

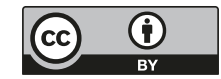

